\title{
Reflecting Bicultural Mechanisms in Waterscape Design and Planning
}

Researcher: Emily Bowerman BLA, MSc in Rural Planning Student Advisor: Dr. Sheri Longboat SEDRD University of Guelph 


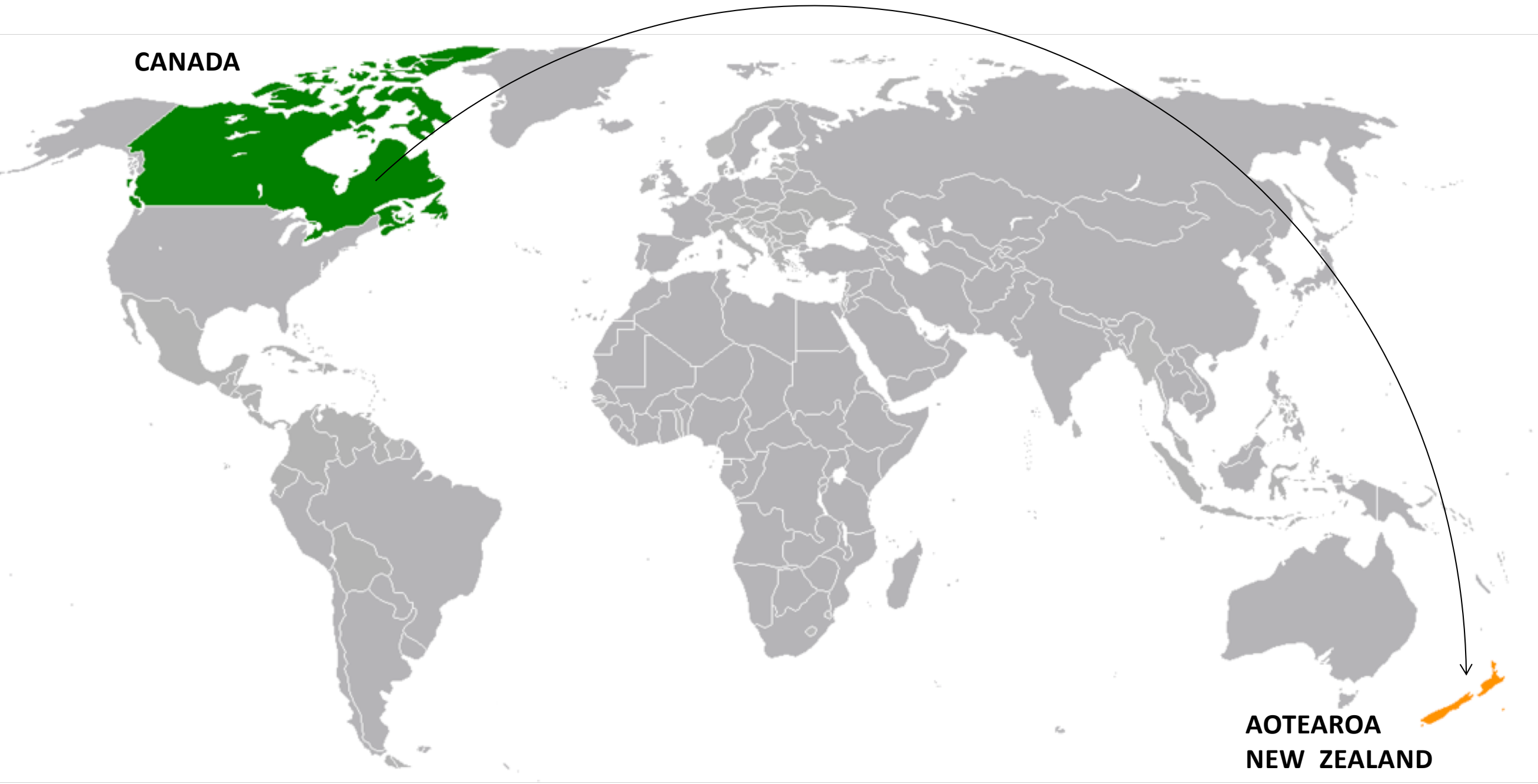




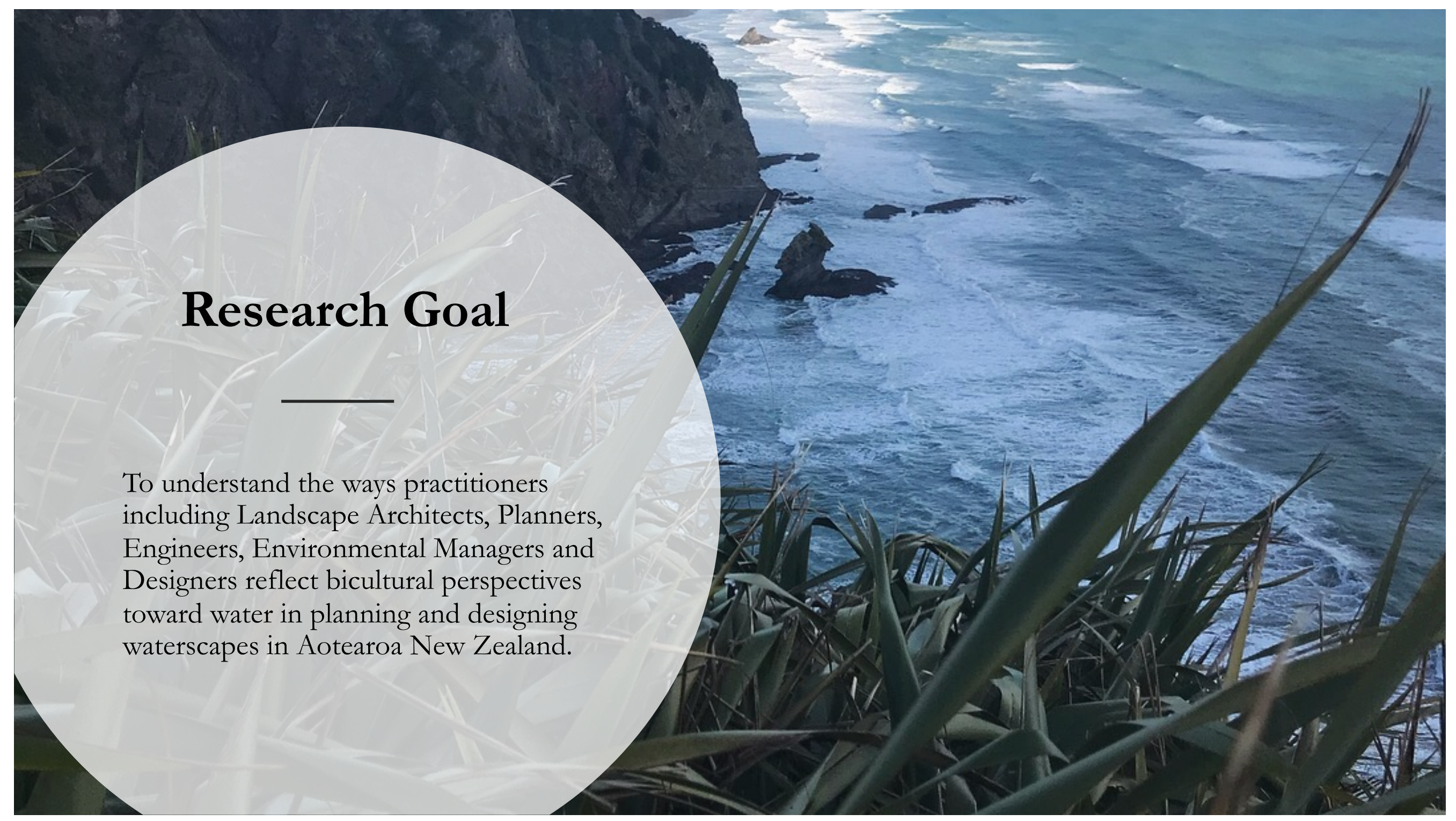




\section{Defining Waterscape}

A landscape in which water relationships are central to the community's social, ecological, recreational, spiritual and cultural interactions.

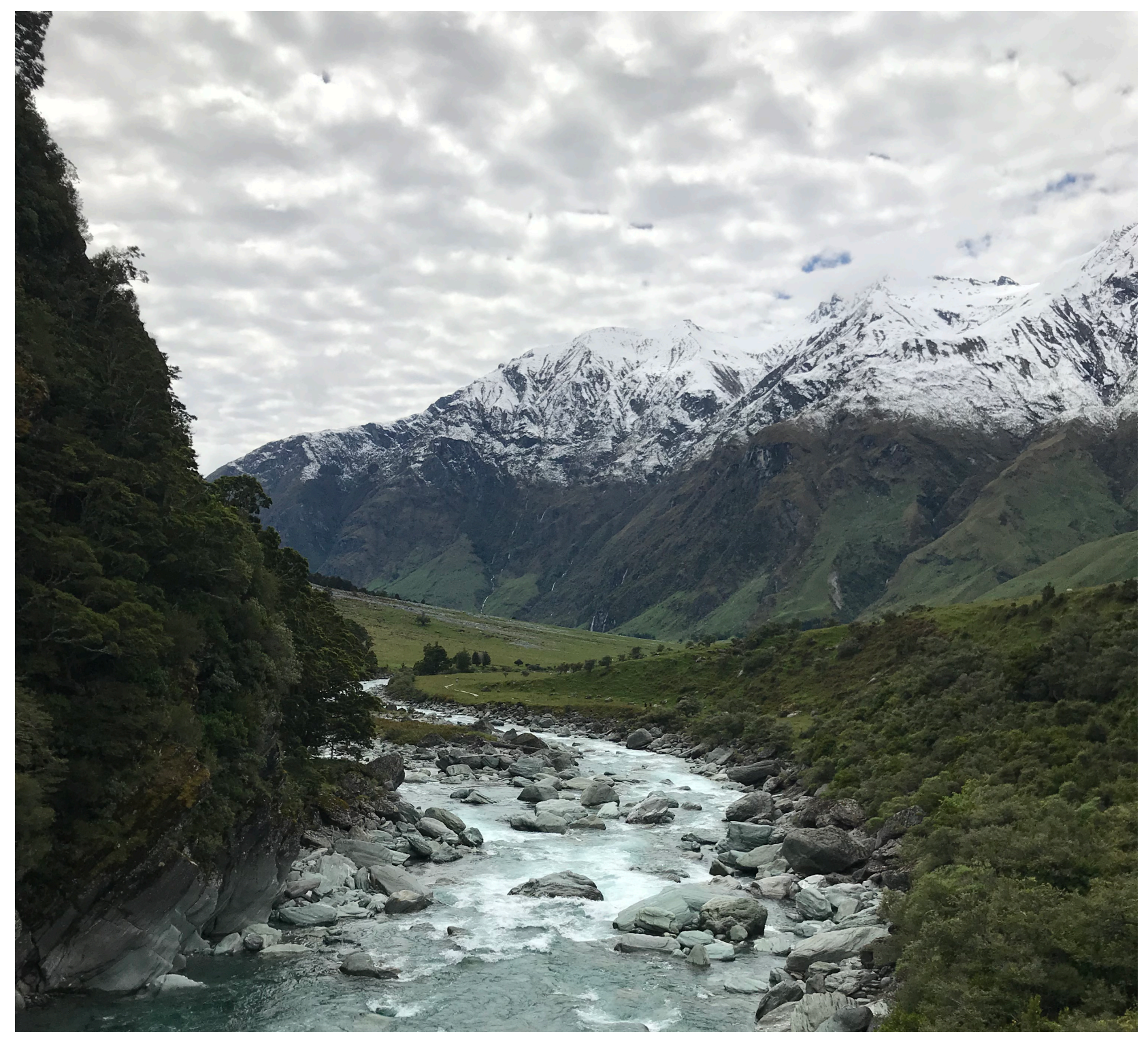


Whanganui River Agreement - Indigenous Rights and Rights of Nature by Elaine C. Hsiao

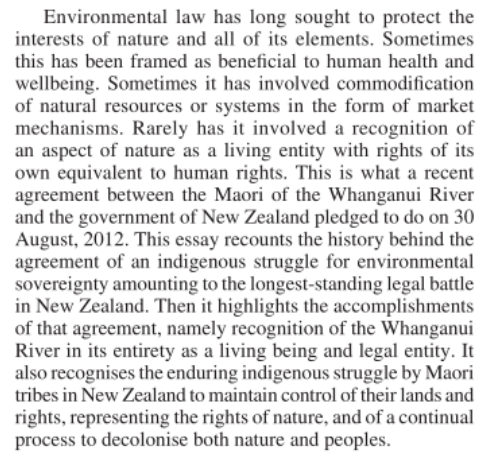
process to decolonise both nature and peoples.

Decolonisation of a River and its People One of the most pervasive legacies of colonisation
remains the civilising mission of European imperialism of "uncivilised" wilderness and peoples the world over.
The project of "improving" non-European or non-Wester peoples and forms of nature through imposition of a predetermined order on all levels of political, sociocultural, legal and economic life, characterised European modernisti and development and conservation. This involved establishing colonial systems of administration that dissupted traditiona lands over to colonial lof governance, and converting wild duction and decorative gardens. A strategy of resistance to colonisation on the par
of peoples whose very cosmology refuses to recognise nature as merely a set of resources for human use an sovereignty. Indigenous peoples, whose culture, identity

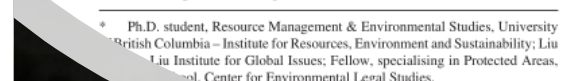

their natural environment may find that assertion of their
own self-determination and cultural preservation are linked to rights, decision making and control over the lands and resources to which they are connected. ${ }^{2}$ In such cases, relocating indigenous sovereignty simul aneously evokes an assertion of environmental sovereignty. Through a
process of reclaiming environmental rights, indigenous sovereignty itself can also be restored. The story of the Whanganui Iwi and Te Awa Tupua is one of so many narratives of intertwined struggle for
decolonisation of both peoples and nature. The Whanganui Iwi share two ancestors, Paerangi and Ruatipua. It is said that Ruatipua "draws lifeforce from the headwaters of the Whanganui River on Mount Tongariro and its tributaries
which stretch down to the sea". The river itself mirrors the which stretch down to the sea". The river itself mirrors the
extension of the descendants of Paerangi and Ruatipua. "Ko au te awa, Ko te awa ko au - I am the river and the river is me". ${ }^{3}$ As such, the Whanganui Iwi recognise the
Whanganui River as their ancestor, as a treasured thing Whanganui River as their ancestor, as a treasured thing (taonga), and as a living being,
Te Awa Tupua is the whole of the Whanganui River, which includes all of its physical and metaphysical elements extending from its tributaries and the mountains to the sea. ${ }^{5}$ The Whanganui River is the longest navigable river sustenance, water, energy and enjoyment For the people of the river, the Whanganui Iwi, Te Awa Tupua is integral to

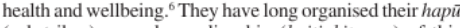
(sub-tribes) around guardianship (kaitiakitanga) of this (life-force) of every extent of the river for come. 'It is this "enduring concept of Te Awa Tupua - the inseparability of the people and River- - which, underpins use the Whanganui River through the kawa and tikan ed by the descendants of Ruatipua and Paer Protecting the River is equivalent to protecting the lead to better protection of the River.

A History of Systemic Rights D The desire of the Whangan
sacred river has endured for over petitions and protests rais

\section{Whanganui River Agreement (2017)}

Assigning legal personhood status to Rivers 

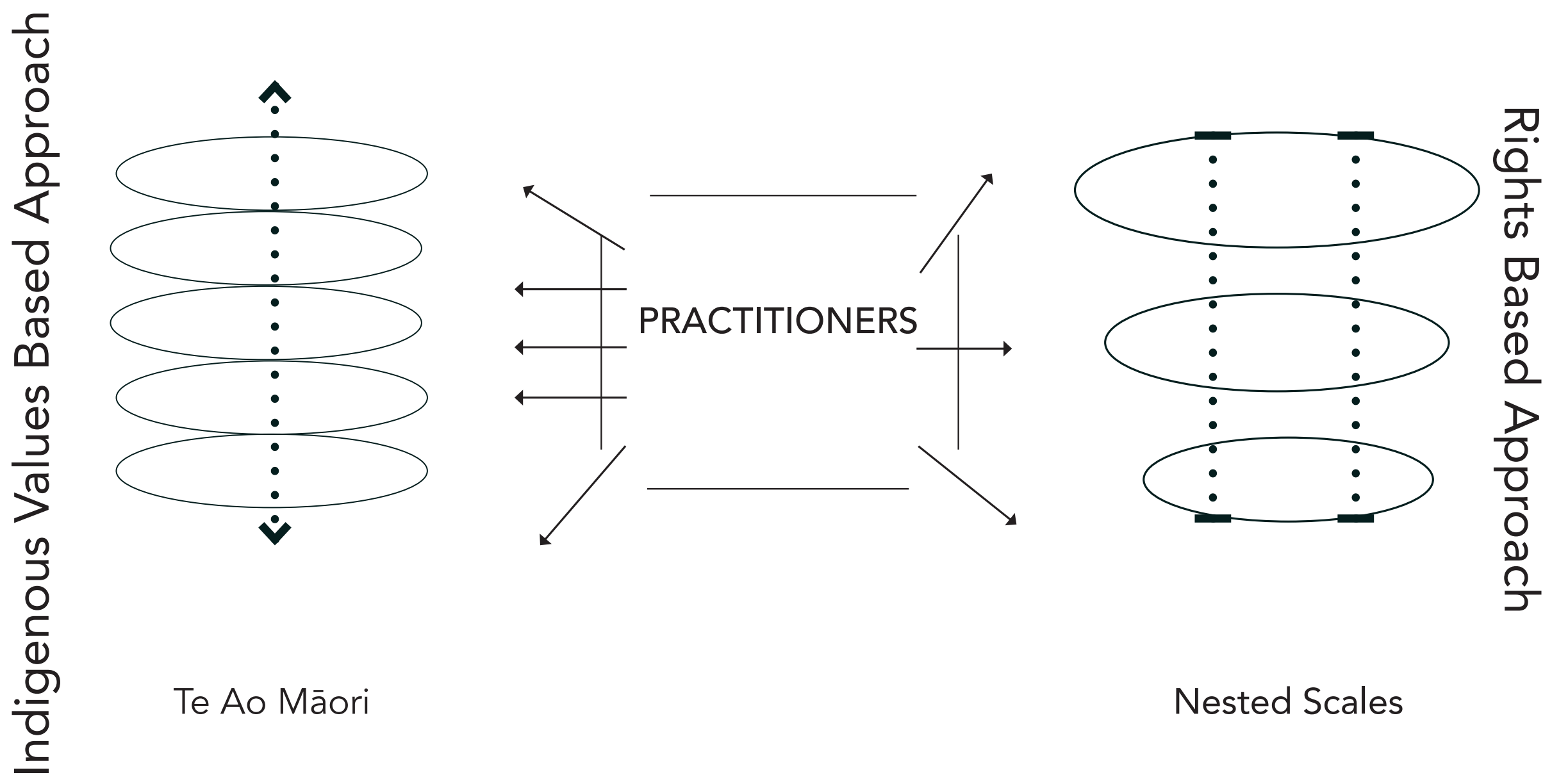

Nested Scales 
Outcomes \& Key Takeaways

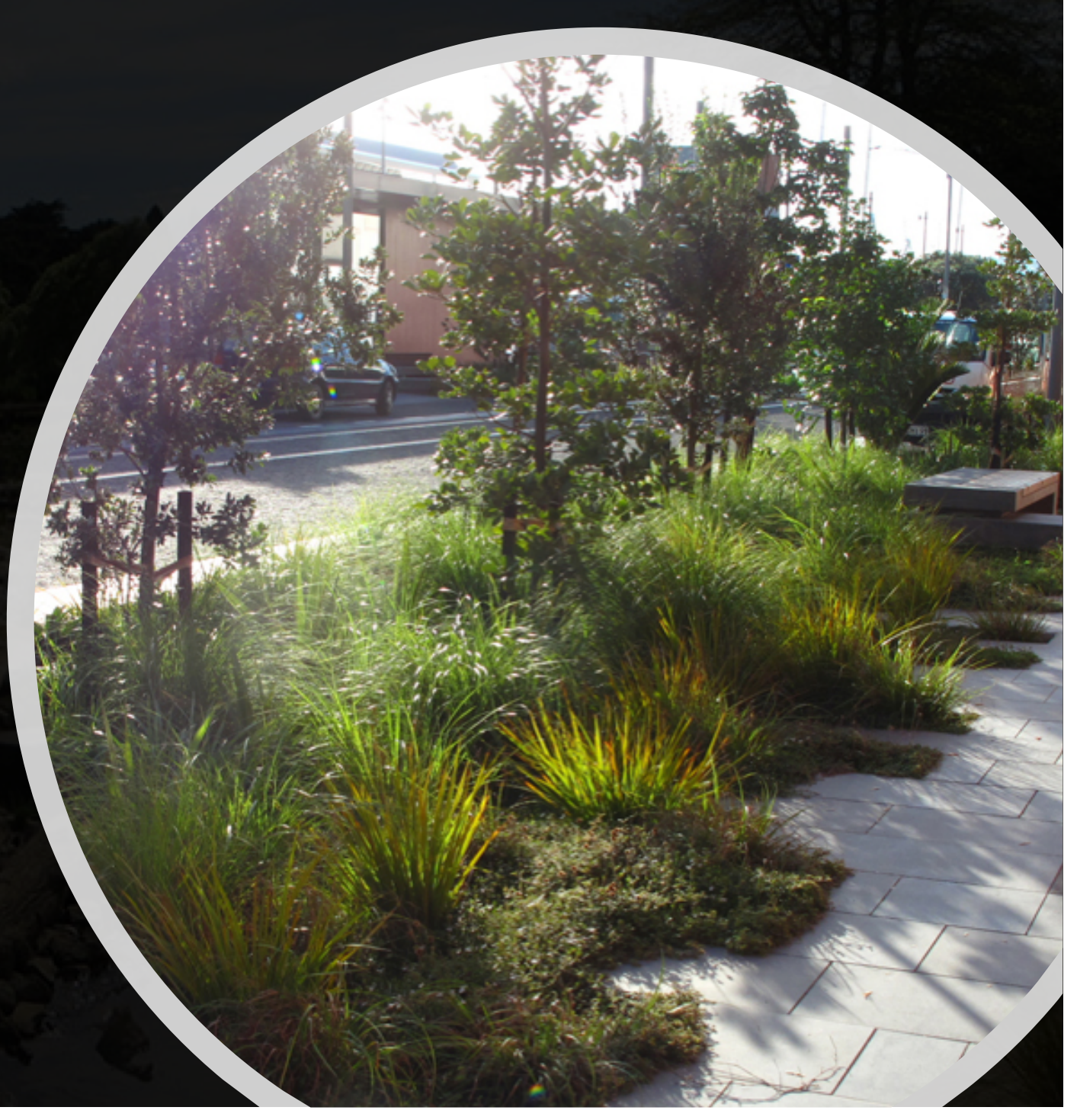


VALUES

\section{Te Aranga Design Principles}

- Give Māori a voice in the urban landscape that was once omitted from the design and planning process

- Value-based approach to design and planning that inform more inclusive and representative project outcomes

- Inform a new "Aotearoa New Zealand" design typology

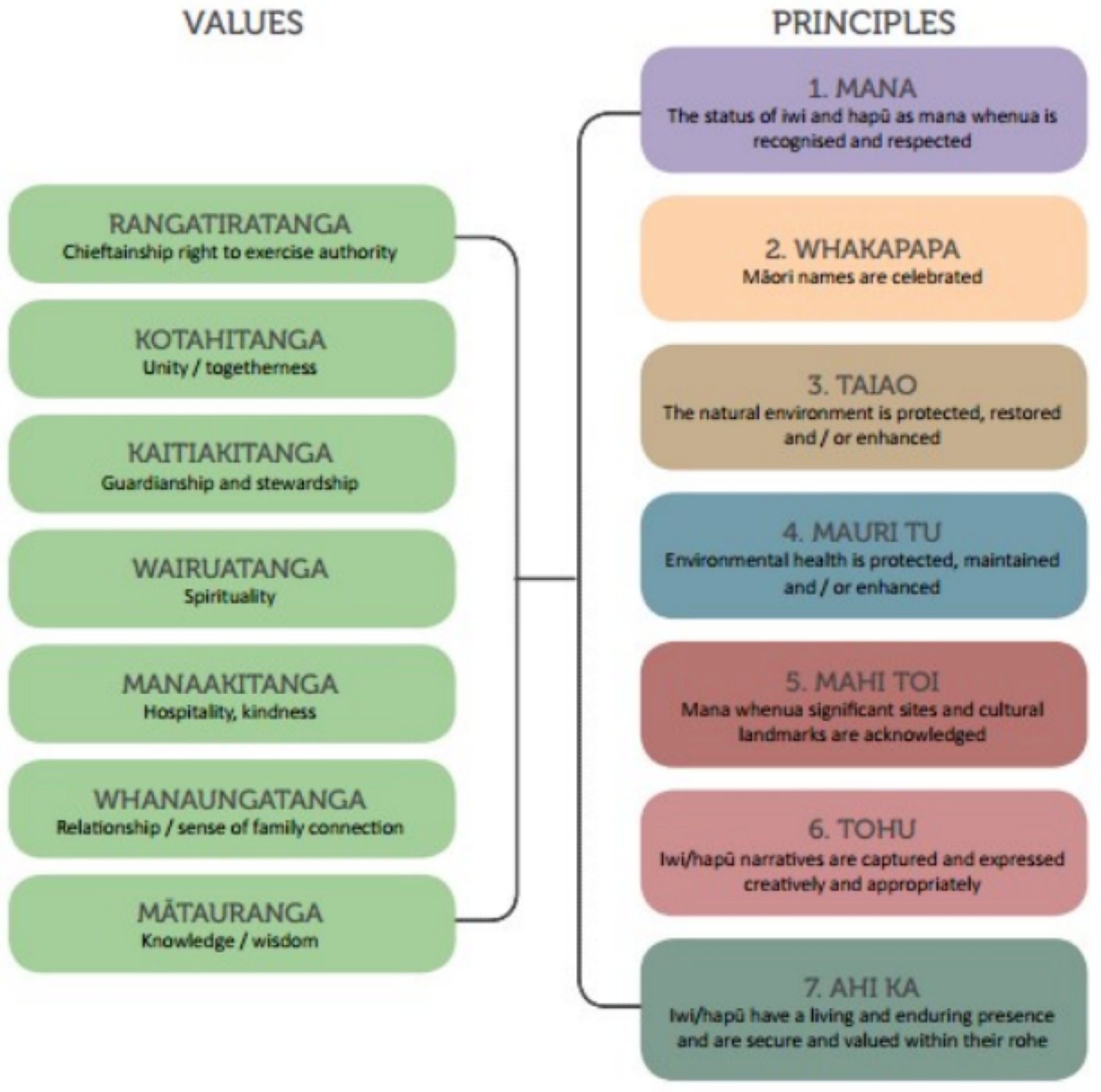




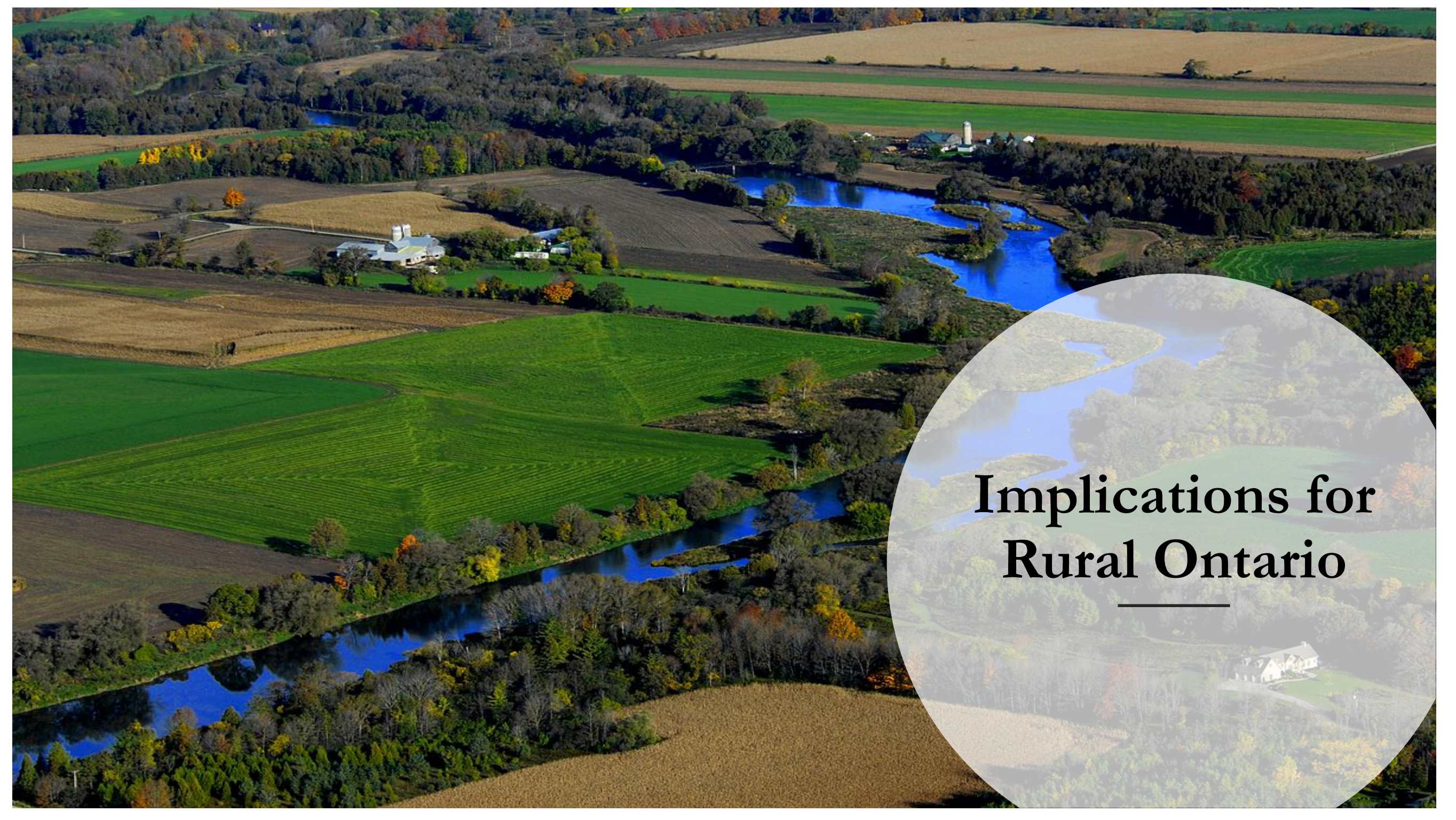




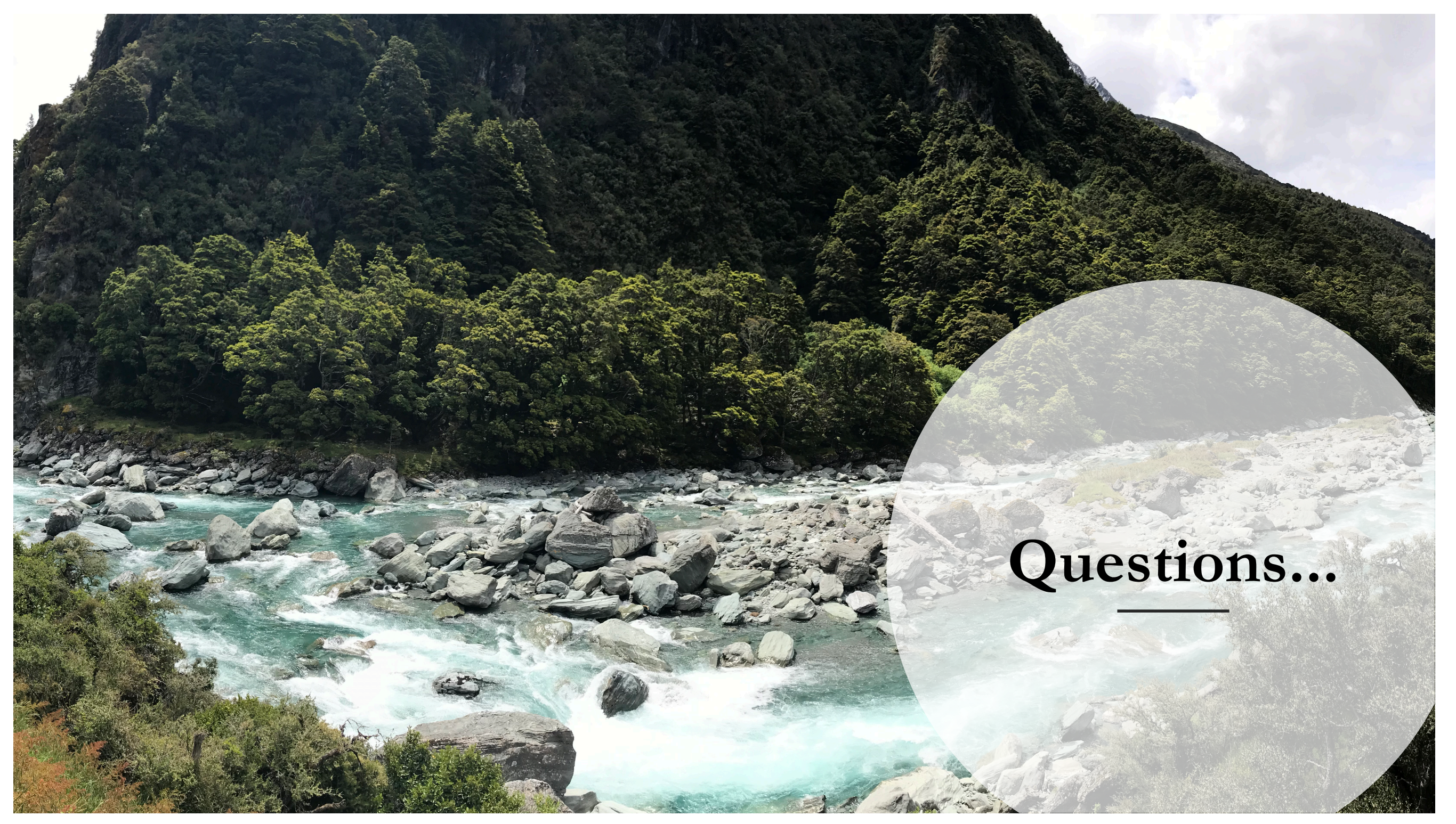




\section{Figures}

\section{- All images are original excluding:}

SLIDE 2 https://en.wikipedia.org/wiki/Canada $\%$ E2\%80\%93New_Zealand_relations

SLIDE 6 https://www.researchgate.net/publication/235671679_Whanganui_River_Agreement_-_Indigenous_Rights_and_Rights_of_Nature SLIDE 9 https://en.wikipedia.org/wiki/Woolwich,_Ontario 